\title{
Cell-based therapy for the treatment of female stress urinary incontinence: an early cost-effectiveness analysis
}

\author{
Andreas West VilsbølI ${ }^{1}$, Jakob Munk Mouritsen ${ }^{1}$, Line Park Jensen ${ }^{1}$, Nikolaj Bødker ${ }^{1}$, \\ Annette Willemoes Holst ${ }^{2}$, Cristian P Pennisi*,1 \& Lars Ehlers ${ }^{2}$ \\ ${ }^{1}$ Department of Health Science \& Technology, Faculty of Medicine, Aalborg University, Aalborg, Denmark \\ ${ }^{2}$ Danish Center for Healthcare Improvements, Aalborg University, Aalborg, Denmark \\ *Author for correspondence: Tel.: +45 9940 2419; cpennisi@hst.aau.dk
}

\begin{abstract}
Aim: To perform an early cost-effectiveness analysis of in vitro expanded myoblasts (IVM) and minced myofibers versus midurethral slings (MUS) for surgical treatment of female stress urinary incontinence. Methods: Cost-effectiveness and sensitivity analyses were performed using a decision tree comprising previously published data and expert opinions. Results \& conclusion: In the base case scenario, MUS was the cost-effective strategy with a negative incremental cost-effectiveness ratio compared with IVM and a positive incremental cost-effectiveness ratio compared with minced myofibers. However, the sensitivity analysis indicates that IVM may become an alternative providing greater effect at a higher cost. With the possibility of becoming more effective, IVM treatment would be advantageous over MUS given its reduced invasiveness and lower risks of complications.
\end{abstract}

First draft submitted: 25 August 2018; Accepted for publication: 30 January 2018; Published online: 1 May 2018

Keywords: cell- and tissue-based therapy $\bullet$ economic analysis $\bullet$ healthcare costs $\bullet$ incremental cost-effectiveness ratio $\bullet$ midurethral slings $\bullet$ myoblast transplantation $\bullet$ stress urinary incontinence

Urinary incontinence (UI) is a common medical condition that has a negative impact on the quality of life of individuals of all ages, racial and ethnic groups. The prevalence of UI is about two-to-four-times higher in women than in men, ranging from 11 to $57 \%$ [1]. The most common subtype is stress urinary incontinence (SUI), affecting roughly $50 \%$ of any women with UI [2]. SUI describes a condition where there is an involuntary leak of urine when intra-abdominal pressure rises, for example, when coughing, sneezing, laughing or during other physical activity. SUI has not only a severe impact on quality of life but it also places a substantial economic burden on the healthcare system and society [3-5]. In the USA, for example, it has been estimated that in 1998, the average direct medical cost of SUI amounted US $\$ 5642$ per patient, while the indirect workplace expenses were US $\$ 4208$ [3]. Evidence suggests that these costs have experienced an age-related increase over the last years [5].

The clinical management of SUI is complex and may involve conservative treatments, such as pelvic floor muscle training and pharmacotherapy, as well as surgical procedures. Currently, the gold standard for surgical management of SUI in women is the midurethral sling (MUS), which displays a cure rate of 80-95\% [6-8]. While MUS has a high success rate, $5-20 \%$ of the patients will have persisting incontinence thus needing to undergo sling removal and subsequent treatment [9]. The postoperative complications reach as high as $7.2 \%$ for erosion and the risk of getting a perioperative urinary tract infection is $17.2 \%$ [10]. As an alternative to MUS implantation, with the goal of targeting the underlying etiology rather than relieving the symptoms, cell-based therapies (CBTs) have recently emerged [11]. Among the different modalities of CBT, intraurethral injection of autologous skeletal myoblasts appears as one of the most promising regenerative therapies for SUI [12]. While various large-scale clinical trials are still ongoing, results from the initial clinical studies have shown that these approaches appear to be safe and moderately effective. Remarkably, a recent study has shown that most patients would prefer autologous CBTs rather than surgery for the treatment of incontinence [13]. These procedures require a biopsy taken from the patient to obtain skeletal muscle 
progenitor cells, which are implanted within the external urethral sphincter either immediately after harvesting as minced myofibers (MM) [14,15] or after a period of in vitro myoblast (IVM) expansion [16-18].

Whereas demonstration of clinical efficacy is an important part in the assessment of new regenerative medicine technologies, early health economic evaluations, such as cost-utility analysis, become equally essential for supporting decision-making [19]. An early evaluation of cost-effectiveness can be conducted to evaluate the potential impact of new therapeutic agents when all parameters and their values have been determined. It is common in such an early evaluation that the initial estimates of the model parameters are derived from expert opinion, observational studies, pilot studies or small clinical trials, as done for this study. Even though long-term evidence from randomized controlled trials (RCTs) is unavailable, cost-effectiveness estimations of novel treatments are particularly functional for providing directions in which future research should focus on [20]. Although, early cost-effectiveness modeling provides valuable insights into the clinical and economic value of new therapeutic agents, it does not directly provide a conclusive answer to the question of whether the developer should continue the process [21]. The aim of this study is to estimate the overall cost-effectiveness of CBTs in comparison to the established MUS procedure for the initial treatment of SUI by conducting an early cost-utility analysis.

\section{Materials \& methods}

This cost-effectiveness model describes the average costs and the gain in quality-adjusted life years (QALY) between the three treatment modalities for women with SUI. The calculations are based on a healthcare sector perspective and the time frame is chosen to be 1 year, as it is expected to account for the vast majority of costs and outcomes related to the three treatments of SUI. The healthcare sector perspective was chosen to avoid the problem of double counting of costs, and to focus firmly on resource cost within the healthcare sector. Thus, changes in the use of resources beyond the healthcare sector, such as workplace productivity loss, patient and family costs, are beyond the scope of this study. Only relevant costs, the costs that vary between the alternatives, are included in the analysis. These costs are all estimated in Euros (year 2016-2017 values). The results are presented as pairwise incremental cost-effectiveness ratios (ICERs), which are the ratios of the difference in costs to the difference in QALYs between the treatments. A graphical presentation of the same results is shown in a cost-effectiveness plane, where the ICERs are given by the slopes of the lines between the cost-effectiveness ratios for the alternative treatment modalities. A decision tree was constructed using Tree Age (2016 version, TreeAge Software, MA, USA), which enabled the comparison of cost-effectiveness of the three treatments as illustrated in Figure 1. The decision tree was based on a previously reported model used to assess the cost-effectiveness of conservative versus surgical management of SUI [22]. A representative population of women with SUI was modeled based on a series of assumptions; the patients had to be female with uncomplicated and symptomatic SUI who underwent a normal neurologic examination, had a normal postvoid residual urine volume and were suited for tension-free vaginal tape (TVT) or transobturator tape (TOT) surgery. TVT and TOT were chosen as the surgical treatment modeled for MUS, and is referred to as so onwards. The content of the decision model was selected from evidence-based medical literature and reflects the best-available data on SUI. The available evidence was obtained by systematic literature review using MeSH terms in the PubMed search engine. Key literature on the CBTs was found using (("Myoblasts" [Mesh]) AND "Urinary Incontinence, Stress" [Mesh]), and (“Urinary Incontinence, Stress" [Mesh]) AND "Celland Tissue-Based Therapy" [Mesh]). Specific searches on some probabilities and costs used in the decision tree were also conducted, as these were unattainable through the systematic literature review. Furthermore, to present reliable results, the uncertainty of the analysis was measured using a sensitivity analysis to examine the impact of varying the cure rates of SUI for each of the two CBTs.

\section{Probabilities}

It was assumed that the probability for each of the scenarios 'cured' and 'not cured' was defined as a combined subjective and objective measure. MUS as surgical treatment for SUI has a combined cure rate of $80.9 \%$ as observed in a RCT conducted by Labrie et al. [23]. Morbidities such as mesh erosion, recurrent SUI, de novo urge incontinence and urinary retention requiring release included in this model are based on formerly published studies. Within 1 year of MUS surgery, the probability of mesh erosion was $2.24 \%$, and $84.6 \%$ had sling excision following mesh erosion [10,24]. Conservative treatment was modeled as an alternative to sling excision with an estimated base case of $15.4 \%$. Additionally, it was modeled that $36 \%$ of the patients who had sling excision experienced persistent SUI based on a retrospective cohort study [25]. Base case rates of developing de novo urge after initial treatment with MUS and postoperative use of anticholinergic medication when having developed urge symptoms as a consequence 


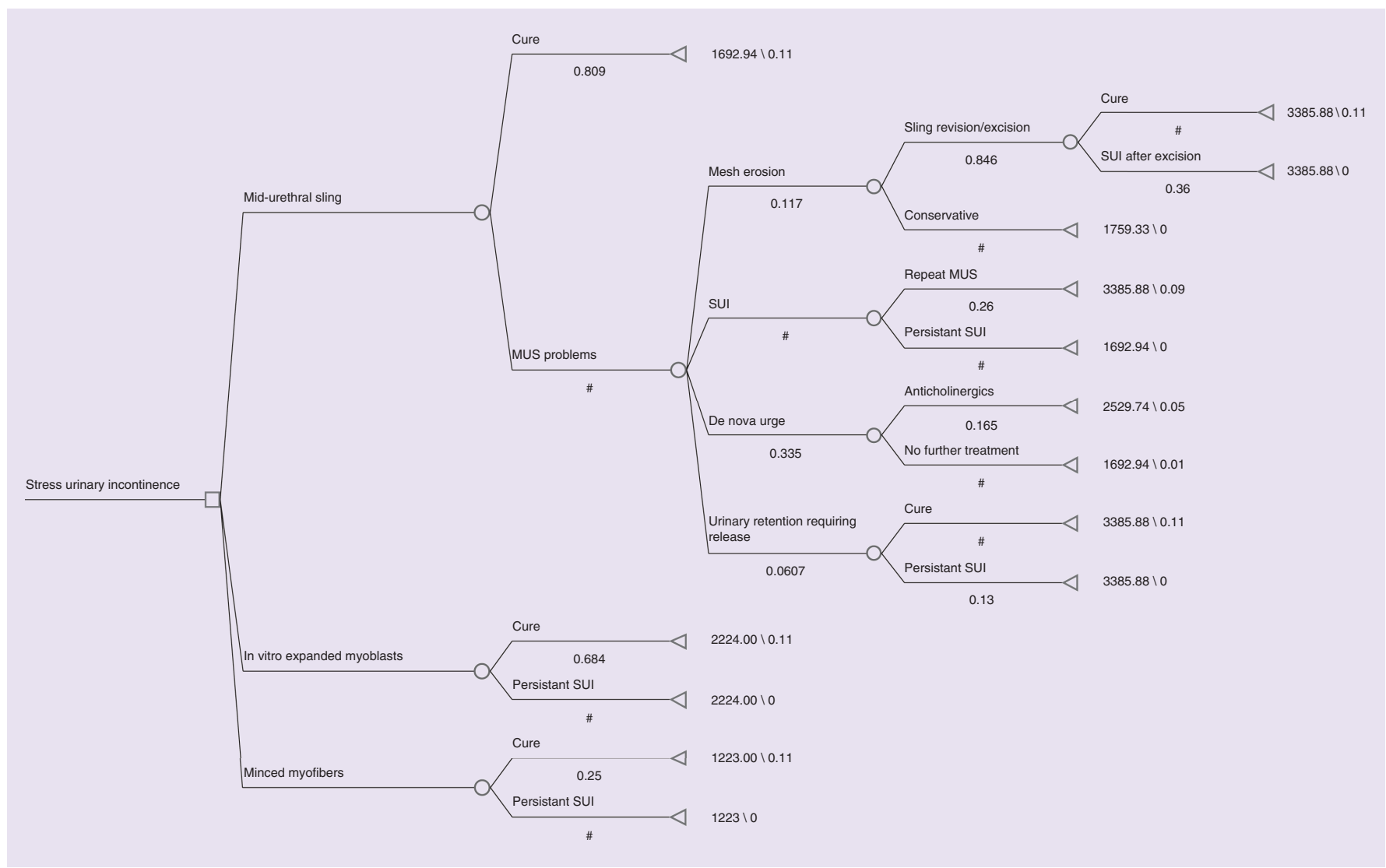

Figure 1. A decision tree modeled with probabilities, health utilities and costs. MUS: Midurethral sling; SUI: Stress urinary incontinence.

of MUS, was modeled after an RCT, which reported probabilities of 6.4 and $16.5 \%$, respectively [10,26]. Patients who developed urinary retention after MUS treatment that required sling release were estimated to $6.01 \%$ in base case [10]. Rardin et al. performed a retrospective study investigating the risk of recurrent SUI after conducting a necessary sling release in which $13 \%$ reported having a recurrence of SUI equal to or worse than the initial baseline [27]. Women with persistent SUI after initial MUS treatment were modeled to receive an additional MUS treatment or no further treatment. However, if SUI persisted after the second MUS treatment, no further treatment would be offered. The probability of persistent SUI was calculated to be $9.3 \%$. In this group, any other MUS problem is included to meet the assumptions of the decision model. After failed MUS, $2.4 \%$ were found to receive a second MUS according to Ford et al. [6]. Cure rate probabilities for IVM were estimated based on three different studies. Two studies from Mitterberger et al. [16,28], and a third study from Blaganje and Lukanovic [18]. These studies showed cure rates of $90 \%(n=20), 79 \%(n=119)$ and $23.7 \%(n=38)$, respectively. A pooled mean was calculated from all three resulting in an estimated base case cure rate of $68 \%$. Although there are other studies in the literature showing similar efficiency for IVM, they were not included here due to lack of definition the 'cured' patient population $[34,35]$. All patients not included in the group of 'cured' were added to the group 'not cured', despite having shown improvements. The same criteria for 'cured' and 'not cured' were applied for each of the treatments to enable comparison. Based on the study of Blaganje and Lukanovic [18], 23.7\% was considered as the lower limit cure rate while based on Mitterberger et al., 90\% was considered as the upper limit [16]. The third treatment alternative, MM, was modeled with base case data from Gräs et al., who investigated this approach for SUI treatment in a Phase I/II pilot clinical trial [15]. A possibility of either cure or persistent SUI was modeled with base case of 25 and 75\%, respectively. The base case and lower limit were assumed to be the same. The calculation was done combining the two groups of 'improved' and 'not cured'. The upper limit was estimated by adding the 'improved' to the 'cured'. All probabilities are shown in Table 1 and used in the decision tree (Figure 1). 


\begin{tabular}{|c|c|c|}
\hline Parameter & Base case & Ref. \\
\hline Probability of cure with MUS & $80.9 \%$ & [23] \\
\hline Probability of problems after MUS surgery & $19.1 \%$ & [23] \\
\hline Probability of mesh erosion following MUS surgery & $2.24 \%$ & [24] \\
\hline Probability of mesh erosion that requires sling revision/excision & $84.6 \%$ & [24] \\
\hline Probability of SUI after sling revision/excision & $36 \%$ & [25] \\
\hline Probability of sustained SUI after MUS surgery & $9.3 \%$ & Estimated \\
\hline Probability of reoperation with MUS due to sustained SUI & $2.4 \%$ & [6] \\
\hline Probability of having de novo urge incontinence after insertion of MUS & $6.4 \%$ & [26] \\
\hline Probability of receiving anticholinergic medicine as treatment of de novo urge incontinence & $16.5 \%$ & [10] \\
\hline Probability of persistent SUI after sling release & $13 \%$ & [27] \\
\hline Probability of cure with IVM & $68.4 \%$ & {$[16,18,28]$} \\
\hline Probability of persistent SUI after treatment with IVM & $31.6 \%$ & {$[16,18,28]$} \\
\hline Probability of cure with MM & $25 \%$ & [15] \\
\hline Probability of persistent SUI after treatment with MM & $75 \%$ & [15] \\
\hline
\end{tabular}

\begin{tabular}{|c|c|c|}
\hline Parameter & Base case & Ref. \\
\hline Health utility value of no incontinence & 0.93 & [29] \\
\hline Health utility value for SUI & 0.71 & [29] \\
\hline Health utility value for treatment of de novo urge with anticholinergic medication & 0.81 & [29] \\
\hline Health utility value for de novo urge after MUS operation & 0.74 & [29] \\
\hline Health utility value for repeated MUS operation & 0.89 & {$[23,29]$} \\
\hline
\end{tabular}

\section{Effects}

Effectiveness values were measured in QALYs and are shown in Table 2. QALY can be used to assess the burden of a specific disease in relation to healthy subjects or subjects suffering from an unrelated disorder. It is a generic measure used to estimate the value for money in economic evaluation. One QALY is equivalent to 1 year in perfect health regardless of age, gender, job and financial circumstances. To estimate the number of gained QALYs, each life-year is multiplied by the relevant health utility weights reflecting the patients' relative health states. Health utility weights can range from $0-1$, where 0 represents death and 1 represent perfect health; in theory, it is possible to have a health utility weight below 0 [36]. Since a 1-year time frame was used in this study, the health utilities from Mittmann et al. were converted to QALYs [29]. The health utility weight for no postoperative incontinence was 0.93 . This value represents healthy women in the age range 12 to $>80$. The health utility weight for SUI was 0.71 representing women in the age range 20 to $>80$. The modeled branches 'repeated MUS', 'anticholinergic treatment' for de novo urge and de novo urge with 'no further treatment' had a different utility score. The health utility weight for 'repeated MUS' was based on the probabilities for successful MUS, where $81 \%$ of the 'repeated MUS' would end up having a health utility weight of 0.93 but $19 \%$ would still have a score of 0.71 . Summed up, patients with 'repeated MUS' end up having a health utility of 0.89 . Based on data from Wu et al. [37], treatment of de novo urge with 'anticholinergic medication' used in the decision tree was 0.81 , whereas the health utility value for de novo urge with 'no further treatment' after MUS was 0.74. The calculated QALYs used in the decision tree are an expression for the utility gained per treatment. Based on a QALY calculation, a gain from receiving a curative treatment was calculated to be 0.11 proportional gained QALY over a year. It is assumed that cured SUI patients, despite which of the treatments used, had a gain of 0.11 QALY, as illustrated in the decision tree. 
Table 3. Parameters of costs for different outcomes.

\begin{tabular}{|l|l|}
\hline Parameter & Base case ( $\in$ R) \\
\hline Cost of outpatient MUS & 1693 \\
\hline Cost of sling excision for mesh erosion & 1693 \\
\hline Cost of anticholinergic treatment & 442 \\
\hline Cost of pelvic floor muscle training & 66 \\
\hline Cost of sling release for urinary retention & $130]$ \\
\hline Cost of MM & [31] \\
\hline Cost of IVM & [32] \\
\hline IVM: In vitro myoblast approach; MM: Minced myofiber approach; MUS: Midurethral sling. & 2223 \\
\hline
\end{tabular}

\section{Costs}

All costs are summarized in Table 3. It was assumed that each of the three treatments for SUI would be standard treatment and have identical follow-up periods, to allow for comparison. Furthermore, the analysis was conducted from a public health system perspective in regard to analyzing the direct costs, thus excluding the extra societal costs such as loss of employment productivity and future costs. Cost estimates on the MUS treatment are based on the Danish diagnosis-related group (DRG) rates, which represent the average costs of a defined group in the healthcare system by the Danish Health and Medicines Authority [30]. Costs related to outpatient MUS were estimated to $€ 1693$ based on DRG 1314 "Simple gynecologic operation" in which "Vaginal uretrocystopexy with sling" and "Vaginal uretrocystopexy with sling through foramen obturator" are included [30]. The "anticholinergic treatment" for de novo urge has an estimated cost of $€ 836$ based on cost of defined daily dosage for oxybutynine, which is used as standard drug treatment for urge incontinence in Denmark. Cost related to pulsed magnetic field therapy was $€ 66$, estimated from the price of four visits at a physiotherapist. A visit to a Danish physiotherapist was estimated to $€ 22.8$ for the first visit, and $€ 14.5$ for each of the additional three visits. These costs were estimated based on the reimbursement level from a physiotherapist clinic in Denmark [32]. Based on a study by Nafees [33], who compared the manufacturing costs for allogeneic versus autologous cell therapies, the cost for IVM was estimated to be $€ 2224$. This value includes the average costs for donor materials, operating the manufacturing facility, cell expansion, packaging and transfer to the hospital. The surgery costs were estimated as the average between 2016 and 2017 of the Danish DRG rate PG06B "Cystoscopy, complicated or urethral surgery or puncture of the prostate". A detailed description on how the total cost for IVM was calculated is included as supplementary information (Supplementary Tables $1 \& 2$ ). The cost of MM procedure was estimated to be $€ 1223$, considering the treatment to be coded as the same DRG rate as for MUS, except for the sling material used for MUS. The cost estimations for CBT procedures have been validated through personal communication with researchers that have been involved in the respective clinical trials. All base case scenarios values are listed in Tables 1-3.

The cost-utility analysis was further supplemented by one-way sensitivity analyses. Key variables were identified in the model as the probabilities of cure rates, and reasonable sensitivity ranges for these inputs were determined. The sensitivity ranges were guided by existing data.

\section{Results}

Based on the base case scenarios, the two novel CBTs were compared with the MUS treatment. A negative ICER was calculated when comparing IVM to MUS (i.e., MUS was better and cheaper than IVM) and an ICER of €9527/gained QALY when comparing MM to MUS treatment (i.e., MUS was better and cheaper than IVM). Both ICERs consolidate the MUS treatment as the preferred strategy for treatment of SUI.

Figure $2 \mathrm{~A}$ shows the base case scenarios for all treatments. It is illustrated that MUS is more effective than the two CBTs, but more expensive than MM. IVM is both more expensive and less effective than MUS, hence being dominated and not cost-effective. If the cure rate for the CBTs was $\geq 0.862$, requiring the cure rate for IVM to increase with 26\% from base case values and MM with 345\%, they would be the preferred treatments over MUS.

Figure 2B shows a one-way sensitivity analysis with probabilities as variables for IVM. A one-way sensitivity analysis was also made for MM with probabilities as variable, resulting in a QALY gain of 0.08. Although, this did not lead to any change in regard to which treatments were to be cost-effective. However, with the probabilities for IVM being $90 \%$, the QALY gain is 0.10 , superior to the 0.09 for MUS. The sensitivity analysis resulted in an ICER of $€ 42940$ /per QALY gained for IVM, thus each treatment is $€ 429.4$ more expensive with a 0.01 gain in effect. 


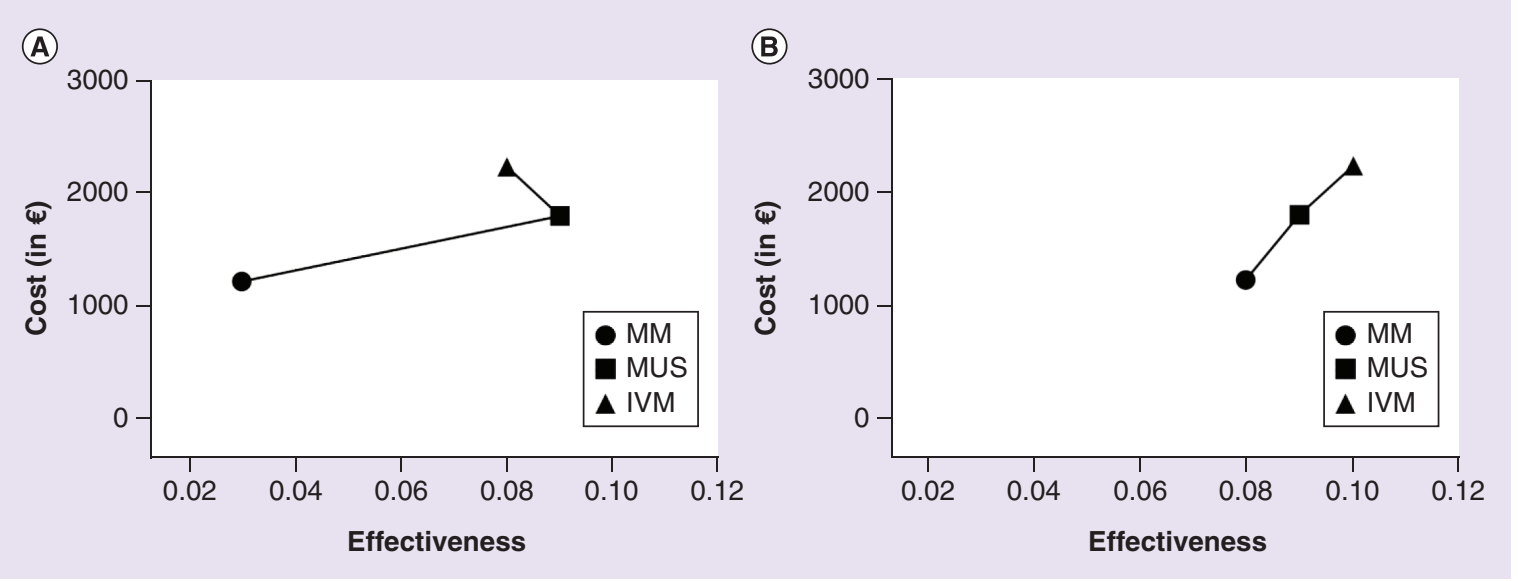

Figure 2. Cost-effectiveness analysis for cell-based therapies versus midurethral slings for the treatment of female stress urinary incontinence. (A) A cost-effectiveness analysis based on the base case scenarios of the three different treatment approaches. Note that the IVM approach is dominated by the MUS procedure. (B) A cost-effectiveness analysis based on the sensitivity analysis of IVM with the upper limit scenario. Note that IVM is more effective, but more expensive.

IVM: In vitro myoblast; MM: Minced myofiber technique; MUS: Midurethral sling.

Furthermore, the sensitivity analysis resulted in an ICER of $€ 57160$ saved per QALY loss for MM, resulting in cost savings on $€ 571.6$ per patient with a 0.01 loss in effectiveness. One-way sensitivity analysis was made with cost as a variable for all treatments, but did also not have a significant impact, as the IVM did not become as inexpensive as MUS and MUS did not become as costly as IVM. However, if IVM should be less costly than MUS, the cost would have to decrease with $23.9 \%$.

\section{Discussion}

Given the increasing demand of financial resources for the healthcare and taking into account the considerable economic impact of SUI [3-5], it is critical to perform early cost-effectiveness assessment of potential new regenerative medicine therapies. In this direction, this study provides a model to assess the cost-effectiveness of CBTs in comparison to the established MUS therapy for surgical management of SUI in women.

The base case values illustrated in Figure 2A reveal that MM has the least expenditures per treatment but also the lowest gain in QALY. The sensitivity analysis of MM with an upper limit of probabilities, which gives a QALY gain of 0.08 , did not dominate MUS treatment. With the currently available evidence, it is therefore unlikely that MM would become an established modality of treatment. On the other hand, IVM is dominated by the MUS treatment, hence the negative ICER, which indicates that IVM is both costlier and less effective. However, the one-way sensitivity analysis based on the upper limit cure rate for IVM indicates that IVM may become more effective as compared with the standard MUS procedure. Furthermore, the sensitivity analysis indicated that IVM has a QALY gain of 0.10 but is more expensive. In the best-case scenario, IVM may be the preferred option for providing a greater effect at a higher cost, considering the less invasive nature of the intervention and the reduced risk of severe complications [38]. In addition, with the rising number of CBTs under development, it is feasible that the costs of cell expansion will be significantly reduced in the future, further reducing the cost of the IVM procedure. For allogeneic stem cell-based therapies, the costs for large-scale expansion are currently displaying a tendency to decrease, mainly due to reduced costs of consumables as the market grows and increased automation of the process [39]. Although the economics of autologous large-scale expansion is challenged by the strict regulation of cell-based advanced therapies [40,41], it is worth mentioning that alternative regulatory pathways exist, such as the Hospital Exemption route in Europe, which allow delivering the treatment to patients at public hospitals at a smaller, noncommercial scale [42]. Besides the reduced costs, it is likely that the effectiveness of the IVM procedures will improve as better quality cells become available for clinical use. 


\section{Limitations of the present study}

One of the limitations of our model is related to the different measures used to evaluate the outcome of the different treatments. Indeed, there is a lack of uniform reporting tools to define the outcome of SUI surgical interventions [43,44]. To circumvent this issue, we assumed that all patients considered 'cured' within all treatment groups, had the same QALY of 0.93 as women without a 'national population health survey'-defined chronic condition in the age range of 12 to $>80$ years. Both CBTs used questionnaires to define 'cured', 'improved' and 'not cured' without using QALY, and while QALY for MUS was available, it was not subgrouped. It is crucial to consider the possibility of a varying QALY for all three treatments after being cured. It is not certain that a patient's QALY after treatment with MUS or CBTs will reach as high as 0.93 . In addition, it is notable that MUS only treats the symptoms of the disease, whereas CBTs target the actual cause, namely degeneration of muscle tissue. This fact can ultimately have an impact on the long-term effects. In perspective, there is a clear need for a consensus, for example, using QALY based on the same multiattribute health status classification system as an international comparable parameter, to promote comparison between studies within the field of UI. Another limitation is related to the fact that treatments do not usually have the same follow-up period. For instance, one of the studies included in the IVM group [18] had a follow-up of 6 months, while all other studies (IVM, MUS and MM) had a follow-up of 1 year. In our model, to allow for comparison, we have therefore assumed that the cure rate reported in this study remained unchanged 6 months after the study was finished.

Regarding the estimation of costs based on the DRG rates, it is worth mentioning that these rates may not accurately reflect true costs for one specific procedure. For instance, the rate that defines the cost of MUS is a "simple gynecologic operation". This rate represents the average costs of a defined group in the healthcare system, in this case covering 25 different operations. For the IVM procedure, the costs associated with the DRG rate PG06B may increase if cell injection is accompanied by complementary therapies, such as transvaginal electrical stimulation [17].

It is also worth discussing that the proposed model of the decision tree and its outcomes is only as strong as the assumptions and evidence the model is based on. The level of evidence used in this study was RCTs for the MUS treatment and case series and clinical pilot studies for the CBTs. Occasionally, when strong-evidence data were not available, the estimates relied on expert opinions. Thus, despite the attempt of building the model with the best available evidence, the conclusions of this study should be taken with caution.

\section{Conclusion}

The economic analysis in this work clearly indicates that MUS therapy is the cost-effective treatment option for women with SUI. The results were driven by the high success rate of MUS compared with the less established IVM and MM procedures. However, the sensitivity analysis indicates the potential of IVM as an alternative with both greater effect and higher costs compared with MUS. With the possibility of becoming more effective, the IVM treatment would be advantageous compared with MUS given its reduced invasiveness and lower risk of adverse events. Important economic questions were raised on whether IVM could reduce its production costs and improve health outcome in pursuit of becoming cost-effective thus attracting further investment. In addition, this study stresses the need of obtaining generic utility values and cure rate probabilities from RCTs. This will enhance the ability to develop more accurate cost-utility models, which will allow assessing the best treatment for women affected by SUI.

\section{Supplementary data}

To view the supplementary data that accompany this paper please visit the journal website at: www.futuremedicine.com/doi/suppl/10.2217/rme-2017-0124

\section{Acknowledgements}

A special thank should be addressed to the M Blaganje and S Gräs for their expert opinions on the topic of the CBTs.

\section{Financial \& competing interests disclosure}

The authors have no relevant affiliations or financial involvement with any organization or entity with a financial interest in or financial conflict with the subject matter or materials discussed in the manuscript. This includes employment, consultancies, honoraria, stock ownership or options, expert testimony, grants or patents received or pending, or royalties.

No writing assistance was utilized in the production of this manuscript. 


\section{Summary points}

- An early economic evaluation is an important part in the overall assessment of regenerative medicine therapies, providing directions in which future research should focus on.

- In this article, the likely cost-effectiveness of two modalities of cell-based therapy have been compared with the standard surgical treatment for female stress urinary incontinence.

- Minced myofiber therapy has the least expenditure per treatment but also the lowest gain in quality-adjusted life years. It is therefore unlikely that this modality would become an established therapy for stress urinary incontinence.

- In vitro expanded myoblast (IVM) therapy is dominated by the midurethral sling treatment. However, one-way sensitivity analysis based on the upper limit cure rate shows that IVM may become more effective than midurethral sling.

- The rising availability of cell-based therapies will likely improve the manufacturing efficiency and costs for allogeneic cell-based therapies, opening the perspective for IVM to become the cost-effective alternative.

- This study stresses the need of defining standardized outcomes, obtaining generic utility values and cure rate probabilities from randomized clinical trials, to enhance our ability to develop more accurate cost-utility models.

\section{Ethical conduct of research}

The authors state that they have obtained appropriate institutional review board approval or have followed the principles outlined in the Declaration of Helsinki for all human or animal experimental investigations. In addition, for investigations involving human subjects, informed consent has been obtained from the participants involved.

\section{Open access}

This work is licensed under the Attribution-NonCommercial-NoDerivatives 4.0 Unported License. To view a copy of this license, visit http://creativecommons.org/licenses/by-nc-nd/4.0/

\section{References}

Papers of special note have been highlighted as: $\bullet$ of interest

1. Contreras Ortiz O. Stress urinary incontinence in the gynecological practice. Int. J. Gynaecol. Obstet. 86(Suppl.), S6-S16 (2004).

2. Reynolds WS, Dmochowski RR, Penson DF. Epidemiology of stress urinary incontinence in women. Curr. Urol. Rep. 12(5), 370-376 (2011).

3. Birnbaum HG, Leong SA, Oster EF, Kinchen K, Sun P. Cost of stress urinary incontinence: a claims data analysis. Pharmacoeconomics 22(2), 95-105 (2004).

4. Subak LL, Brown JS, Kraus SR et al. The 'costs' of urinary incontinence for women. Obstet. Gynecol. 107(4), 908-916 (2006).

5. Chong EC, Khan AA, Anger JT. The financial burden of stress urinary incontinence among women in the United States. Curr. Urol. Rep. 12(5), 358-362 (2011).

6. Ford AA, Rogerson L, Cody JD, Ogah J. Midurethral sling operations for stress urinary incontinence in women. Cochrane Database Syst. Rev. (7), CD006375 (2015).

7. Taha D-E, Wadie BS. Pubovaginal sling, the godfather of midurethral slings that remained so. J. Acute Dis. 4(2), 91-96 (2015).

8. Hakim L, De Ridder D, Van der Aa F. Slings for urinary incontinence and the application of cell-based therapy. Adv. Drug Deliv. Rev. 82-83, 22-30 (2014).

9. Osborn DJ, Dmochowski RR, Harris CJ et al. Analysis of patient and technical factors associated with midurethral sling mesh exposure and perforation. Int. J. Urol. 21(11), 1167-1170 (2014).

10. Schimpf MO, Rahn DD, Wheeler TL et al. Sling surgery for stress urinary incontinence in women: a systematic review and metaanalysis. Am. J. Obstet. Gynecol. 211(1), 71.e1-71.e27 (2014).

11. Hart ML, Izeta A, Herrera-Imbroda B, Amend B, Brinchmann JE. Cell therapy for stress urinary incontinence. Tissue Eng. Part B Rev. 21(4), 365-376 (2015).

- Provides a comprehensive overview of the different cell-based therapies available for the treatment of stress urinary incontinence.

12. Smaldone MC, Chancellor MB. Muscle-derived stem cell therapy for stress urinary incontinence. World J. Urol. 26(4), 327-332 (2008).

13. Wright B, Emmanuel A, Athanasakos E et al. Women's views on autologous cell-based therapy for postobstetric incontinence. Regen. Med. 11(2), 169-180 (2016).

- Provides a valuable, often overlooked perspective from the patients' side in the topic of autologous cell-based therapies for incontinence. 
14. Yiou R, Hogrel J-Y, Loche C-M et al. Periurethral skeletal myofibre implantation in patients with urinary incontinence and intrinsic sphincter deficiency: a Phase I clinical trial. BJU Int. 111(7), 1105-1116 (2013).

15. Gräs $S$, Klarskov N, Lose G. Intraurethral injection of autologous minced skeletal muscle: a simple surgical treatment for stress urinary incontinence. J. Urol. 192(3), 850-855 (2014).

- Presents the results of a Phase I/II clinical trial using a technically simple cell-based therapy for stress urinary incontinence based on minced skeletal muscle fibers.

16. Mitterberger M, Marksteiner R, Margreiter E et al. Autologous myoblasts and fibroblasts for female stress incontinence: a 1-year follow-up in 123 patients. BJU Int. 100(5), 1081-1085 (2007).

- One of the pioneering studies in cell-based therapy for the treatment of female stress urinary incontinence, representing a landmark in the field.

17. Blaganje M, Lukanović A. Intrasphincteric autologous myoblast injections with electrical stimulation for stress urinary incontinence. Int. J. Gynaecol. Obstet. 117(2), 164-167 (2012).

18. Blaganje M, Lukanović A. Ultrasound-guided autologous myoblast injections into the extrinsic urethral sphincter: tissue engineering for the treatment of stress urinary incontinence. Int. Urogynecol. J. 24(4), 533-535 (2013).

19. Koerber F, Rolauffs B, Rogowski W. Early evaluation and value-based pricing of regenerative medicine technologies. Regen. Med. 8(6), 747-758 (2013).

- Demonstrates the need of timely economic evaluation of stem-cell therapies to support succesful decision making and to define research directions.

20. Hartz S, John J. Contribution of economic evaluation to decision making in early phases of product development: a methodological and empirical review. Int. J. Technol. Assess. Health Care. 24(4), 465-472 (2008).

21. Buisman LR, Rutten-Van Mölken MPMH, Luime JJ, Uyl-De Groot CA, Redekop WK. The early bird catches the worm: early cost-effectiveness analysis of new medical tests. Int. J. Technol. Assess. Health Care. 32(12), 46-53 (2016).

22. Richardson ML, Sokol ER. A cost-effectiveness analysis of conservative versus surgical management for the initial treatment of stress urinary incontinence. Am. J. Obstet. Gynecol. 211(5), 565.e1-565.e6 (2014).

- Settles the basis for cost-utility analysis of surgical treatments for urinary incontinence.

23. Labrie J, Berghmans BLCM, Fischer K et al. Surgery versus physiotherapy for stress urinary incontinence. N. Engl. J. Med. 369(12), 1124-1133 (2013).

24. Hammad FT, Kennedy-Smith A, Robinson RG. Erosions and urinary retention following polypropylene synthetic sling: Australasian survey. Eur. Urol. 47(5), 641-647 (2005).

25. Tijdink MM, Vierhout ME, Heesakkers JP, Withagen MIJ. Surgical management of mesh-related complications after prior pelvic floor reconstructive surgery with mesh. Int. Urogynecol. J. 22(11), 1395-1404 (2011).

26. Barber MD, Kleeman S, Karram MM et al. Transobturator tape compared with tension-free vaginal tape for the treatment of stress urinary incontinence: a randomized controlled trial. Obstet. Gynecol. 111(3), 611-21 (2008).

27. Rardin CR, Rosenblatt PL, Kohli N, Miklos JR, Heit M, Lucente VR. Release of tension-free vaginal tape for the treatment of refractory postoperative voiding dysfunction. Obstet. Gynecol. 100(5, Part 1), 898 (2002).

28. Mitterberger M, Pinggera G-M, Marksteiner R et al. Adult stem cell therapy of female stress urinary incontinence. Eur. Urol. 53(1), 169-175 (2008).

29. Mittmann N, Trakas K, Risebrough N, Liu BA. Utility scores for chronic conditions in a community-dwelling population. Pharmacoeconomics 15(4), 369-376 (1999).

30. DRG - Takster 2016 - Sundhedsdatastyrelsen.dk (2016). http://sundhedsdatastyrelsen.dk/da/af regning-og-finansiering/takster-drg/takster-2016

31. Kentera (Oxybutynin). Dansk Lægemiddel Information. Pro.Medicin.dk (2017). http://pro.medicin.dk/Medicin/Praeparater/35940

32. Sundhed. Regler for tilskud til fysioterapi. Sundhed.dk (2012). www.sundhed.dk/borger/behandling-og-rettigheder/sygesikring-og-laegevalg/gratis-behandling-og-tilskud/fysioterapi/

33. Malik N. Allogeneic versus autologous stem-cell therapy. BioPharm Int. 25(7), 36-40 (2012).

34. Carr LK, Robert M, Kultgen PL et al. Autologous muscle-derived cell therapy for stress urinary incontinence: a prospective, dose ranging study. J. Urol. 189(2), 595-601 (2013).

35. Peters KM, Dmochowski RR, Carr LK et al. Autologous muscle-derived cells for treatment of stress urinary incontinence in women. J. Urol. 192(2), 469-476 (2014).

36. Drummond MF, Sculpher MJ, Claxton K, Stoddart GL, Torrance GW. Methods For The Economic Evaluation Of Health Care Programmes. Oxford University Press, Oxford, UK (2015).

37. Wu JM, Fulton RG, Amundsen CL, Knight SK, Kuppermann M. Patient preferences for different severities of and treatments for overactive bladder. Female Pelvic Med. Reconstr. Surg. 17(4), 184-189 (2011). 
38. Vaegler M, DaSilva LA, Benz K et al. Cell-based therapy to treat stress urinary incontinence. Which cell type at what cost? [German]. Urol. Ausgabe A 53(3), 354-361 (2014).

39. Lambrechts T, Sonnaert M, Schrooten J, Luyten FP, Aerts J-M, Papantoniou I. Large-scale mesenchymal stem/stromal cell expansion: a visualization tool for bioprocess comparison. Tissue Eng. Part B Rev. 22(6), 485-498 (2016).

40. Hourd P, Ginty P, Chandra A, Williams DJ. Manufacturing models permitting roll out/scale out of clinically led autologous cell therapies: regulatory and scientific challenges for comparability. Cytotherapy 16(8), 1033-1047 (2014).

41. Sipp D, Turner L. U.S. regulation of stem cells as medical products. Science 338(6112), 1296-1297 (2012).

42. Cuende N, Boniface C, Bravery C et al. The puzzling situation of hospital exemption for advanced therapy medicinal products in Europe and stakeholders' concerns. Cytotherapy 16(12), 1597-1600 (2014).

43. Phé V, Zimmern P, Chartier-Kastler E. Outcome measures for stress urinary incontinence treatment: can we minimally agree? World J. Urol. 33(9), 1221-1234 (2015).

44. Luz R, Pereira I, Henriques A, Ribeirinho AL, Valentim-Lourenco A. King's Health Questionnaire to assess subjective outcomes after surgical treatment for urinary incontinence: can it be useful? Int. Urogynecol. J. 28(1), 139-145 (2017). 